\title{
LONGITUDINAL ANALYSIS OF THE RELATIONS BETWEEN PERCEIVED LEARNING ENVIRONMENT, ACHIEVEMENT GOAL ORIENTATIONS, AND LEARNING STRATEGIES: INTRINSIC- EXTRINSIC REGULATION AS A MEDIATOR
}

\author{
Hirotsugu YAMAUCHI ${ }^{1)}$ and Kaori MIKI ${ }^{1)}$ \\ ${ }^{1)}$ Doshisha University, Japan
}

\begin{abstract}
In the present longitudinal study we investigated the relationship between perceived learning environment (Mastery and Performance Focus), achievement goal orientations (Mastery, Performance, and Work-Avoidance Orientations), learning strategies (Deep Processing, Surface Processing, and Self-handicapping), and intrinsic-extrinsic regulation (Intrinsic, Identified, Introjected, and External Regulation). We administered questionnaires to 214 junior high school students at two points in time: one at grade 7 and the other at grade 8 . Significant mean differences between grades were found in several variables. Multiple regression and hierarchical regression analyses revealed that perceptions of the learning environment were predicting achievement goal orientations, and the intrinsicextrinsic regulation mediated between these two sets of variables. Furthermore, learning strategies were influenced by the various goal orientations. Contrary to previous research results, not all learning strategies were influenced by the various goal orientations. The longitudinal proactive effects were examined for all variables, and most variables were influenced by the same variables from the previous year. When the variables in grade 8 were selected as the criteria and variables in grade 7 were selected as predictors, proactive effects, though not strong, were obtained for some predictors.
\end{abstract}

Key words: perception of learning environment, achievement goal orientation, learning strategy, intrinsic-extrinsic regulation, longitudinal analysis

In recent studies, students' perceptions of their learning environment were viewed as antecedents to their achievement learning activities (Ames, 1992; Ames \& Archer, 1988; Anderman \& Anderman, 1999; Anderman \& Midgley, 1997; Blumenfeld, 1992; Church, Elliot, \& Gable, 2001; Peltonen \& Niemivirta, 1999; Roeser, Midgley, \& Urdan, 1996; Urdan, Midgley, \& Anderman, 1998). The results of these investigations have led to the current interest in achievement goal theory. The role of achievement goals as predictors of educationally relevant outcomes has been documented in a number of studies over the past decade.

Within the research on students' achievement motivation, achievement goal theory

This research was supported by Doshisha University's Research Promotion Fund to Hirotsugu Yamauchi.

We acknowledge valuable cooperation of Ms. Izumi Yoshioka and useful comments of Prof. Anastasia Efklides, Prof. Markku Niemivirta, and Prof. Shizuhiko Nishisato. Thanks are also due to the students and the teachers who participated in our research project.

Correspondence concerning this article should be addressed to Hirotsugu Yamauchi, Department of Psychology, Doshisha University, Kamigyo-ku, Kyoto 602-8580, Japan (E-mail: hyamauch@mail.doshisha.ac.jp). 
has been advanced to identify two contrasting primary types of goal orientations. Researchers have adopted varying labels to characterize the two types of goal orientations: mastery focused versus performance focused (Ames, 1992), learning oriented versus performance oriented (Dweck \& Leggett, 1988), task versus ability (Maehr \& Midgley, 1991), and task involvement versus ego involvement (Nicholls, 1984). Conceptually, mastery, learning, and task involvement goals can be distinguished from performance, ability, and ego involvement goals. In this paper, we have adopted the label of mastery and performance. Recently, Elliot and his colleagues proposed a trichotomous achievement goal framework, and later a four parts framework (Elliot \& Church, 1997; Elliot \& Harackiewicz, 1996; Elliot \& McGregor, 2001). In this framework, both the mastery goal and performance goal were differentiated in terms of approach as positive valence and avoidance as negative valence, and thus four independent achievement goals were identified: mastery-approach, mastery-avoidance, performance-approach, and performance-avoidance goals, respectively. However, in this study we adopted the traditional distinction between mastery and performance goals.

\section{Perceived Learning Environment as Predictor of Achievement Goal Orientation}

In reviewing reports and books on school reform, Epstein (1988) pointed out the lack of adequate attention to students; in contrast, attention is given to school improvement at the federal, state, and local levels. Because students labeled as "docile" were found not necessarily to exhibit passive behavior outside the classroom, Epstein argued that students' behavior and attitudes in a school environment must be related to the way in which the classes are organized and what students are required or permitted to do. To recognize alternative school and classroom structures, she proposed the basic building blocks called the Task, Authority, Reward, Grouping, Evaluation, and Time (TARGET) structures. Epstein (1989) further specified the links between TARGET structures and links between developmental changes in TARGET structures.

In recent studies specific school or classroom structures have been found to affect a range of motivational variables. Ames (1992), for example, selected three classroom structures: Task, Authority, and Evaluation and Recognition, and suggested that these structures are used to organize a variety of classroom characteristics assumed to lead students toward the mastery and performance goal orientations. From another point of view, Ames and Archer (1988) examined the salience of mastery and performance goals in actual classroom settings with the following question: Do mastery and performance goal constructs differentiate students' perceptions of their classroom experiences? How do students' perceptions of classroom goals relate to their selection and use of effective leaning strategies? Their research indicated that students who perceived an emphasis on mastery goals in the classroom reported using more effective strategies than others, while students who perceived performance goals as salient tended to focus on their ability. Based on these results, Ames and Archer (1988) argued that the way the individual student interprets and reacts to classroom experiences is a function of the classroom goal orientation.

Yamauchi and Miki (2000) examined high school students' perceptions of the 
learning environment by including perceptions of teachers' and parents' attitudes towards mastery and performance orientation. This corresponds to the Evaluation and Recognition structure. They used canonical correlation analysis to investigate the relations of students' perceived learning environment (PLE) with their achievement goal orientation and learning strategies. The mastery focus in students' PLE, the mastery goal orientation, and the deep processing in self-regulated learning yielded salient positive loadings on the same variate. The authors suggested that this canonical variate represented the intentional learning mode (see description later) (Niemivirta, 1998a; Yamauchi \& Tanaka, 1998). On the other hand, another canonical variate presented salient positive loadings on the performance focus in students' PLE, the performance goal orientation, and the surface processing in self-regulated learning. This variate was considered to represent the adaptive learning mode (also see Niemivirta, 1998a; Yamauchi \& Tanaka, 1998). In the present study, we assumed that students' PLE, that is, perception of teachers' and parents' attitudes towards mastery and performance orientation included in the Evaluation and Recognition structure, would influence achievement goal orientations.

\section{Intrinsic-Extrinsic Regulation as a Mediator between Perception of Learning Environment and Achievement Goal Orientations}

In early research on intrinsic motivation, Deci (1975) suggested that intrinsically motivated behavior is the prototype of self-determined or autonomous activity and that extrinsically motivated behavior tends to undermine students' experience of selfdetermination. The subsequent discussions of self-determination theory suggested that extrinsically motivated behaviors could vary depending on the degree of students' selfdetermination. Deci and Ryan (1985) distinguished four types of extrinsic regulation on a continuum that describes students' self-determination: external, introjected, identified, and integrated regulation. External regulation refers to behaviors regulated by contingencies that are overtly external to students. Introjected regulation yields behaviors that are motivated by internal prods and pressures such as self-esteem relevant contingencies. Identified regulation occurs when a behavior or regulation is adopted by students' self as personally important. Integrated regulation is the most autonomous or self-determined form of extrinsic motivation and stems from the integration of separate identifications into students' coherent sense of self (Rigby, Deci, Patrick, \& Ryan, 1992). Intrinsic regulation focuses on involvement in an activity with emphasis on the process and not on the outcomes of the activity and is characterized by spontaneity, excitement, intense concentration, and joy.

Vallerand's (1997) hierarchical model of intrinsic-extrinsic motivation suggests that social factors influence motivation and that motivation in turn has affective, behavioral, and cognitive consequences. In educational contexts, it seems that the classroom experiences based on teacher-student interaction and the family climate based on parentchild interaction may be more appropriately conceived of as social factors. Yamauchi (2002) assumed that students' perception of teachers' attitudes as a social factor influences the intrinsic-extrinsic motivation of students and this in turn as a mediator affects students' learning strategies. The results of Yamauchi's (2002) study suggested 
two streams of effects: one stream involved more self-regulated attributes whereas the other stream contained less self-regulated variables.

In general, motivational variables in most of the motivation research are used as independent, mediational, or dependent variables. A number of achievement motivation studies have dealt with strength of motivation as an independent variable and some of recent goal theorists have treated intrinsic motivation as dependent variables (e.g., Elliot \& Harackiewicz, 1996). In the present study, however, we assumed that PLE influences intrinsic-extrinsic regulation and that regulation in its turn would play a mediating role between PLE and goal orientation. Because there has been little research examining the role of regulation as a mediator between PLE and goal orientation, we used three types of extrinsic regulations, namely external, introjected, and identified regulations in addition to intrinsic regulation.

\section{Relations between Goal Orientation and Learning Strategy}

A number of studies have argued that mastery goal orientation is beneficial for a wide range of educationally relevant outcomes, while performance goal orientation leads to less positive patterns of motivation and self-regulated learning (e.g., Elliot \& Church, 1997; Midgley, Kaplan, \& Middleton, 2001; Niemivirta, 1998b; Pintrich, 2000; Pintrich \& Garcia, 1991; Wolters, Yu, \& Pintrich, 1996). Other research has identified a workavoidance goal, which is the goal of not working hard and the belief that success is dependent on behaving "nicely" in class (Duda \& Nicholls, 1992).

Students' goal orientations are presumed to be important mediators and determinants of behavioral, cognitive, and affective patterns in achievement situations. Mastery goaloriented students are more likely to believe that effort is the basis for success or failure and they engage themselves in deep strategy processing, while performance goal-oriented students are interested in demonstrating their ability and are involved in surface strategy processing (Ames, 1992; Pintrich \& De Groot, 1990). When students choose the workavoidance goal, they exhibit self-handicapping behaviors to ensure a safe outcome in success or in failure: a success following low effort maximally enhances students' perceived ability and a failure may be attributed to insufficient effort. Here, the highest ability is associated with success with minimal effort and the lowest ability is exhibited by failure with maximal effort (Pintrich \& Garcia, 1994).

Niemivirta (1998a) presented different motivational-cognitive patterns in a heuristic model that consisted of three distinct learning modes. (1) The intentional learning mode is characterized by an intrinsically motivated and mastery-oriented activity that has as goal the construction of personal knowledge. (2) When the basic motive for self-regulation is to promote personal well-being, one can try to demonstrate one's competence in the adaptive and self-enhancing mode. (3) One can protect the self against esteem-threatening situations in the adaptive and self-protective mode. Thus, students with different goal orientations are likely to adopt different self-reported learning strategies. Yamauchi and Tanaka (1998) investigated the association between goal orientation and learning strategy. They found (a) highly positive correlations between mastery orientation and deep processing, between performance orientation and surface processing, and between work- 
avoidance orientation and self-handicapping, and (b) significantly negative correlations between mastery orientation and self-handicapping, and between work-avoidance orientation and deep processing. These findings suggest that students' use of learning strategies might be related to their goal orientation. As mentioned above, Yamauchi (2002) suggested that there are two streams in the motivational sequence, 'mastery climate $\rightarrow$ more intrinsic regulation $\rightarrow$ deep processing' and 'performance climate $\rightarrow$ more extrinsic $\rightarrow$ surface (and self-handicapping) processing.' Furthermore, he extracted three factors by factor analysis with orthogonal rotation on the questionnaires used. The first factor was interpreted as the intrinsic stream, and included mastery focus, intrinsic regulation, identified regulation, and deep processing. The extrinsic stream was divided into two parts: the one factor was defined as an extrinsic stream involving PLE and regulation, and the other factor as an extrinsic stream involving regulation and learning strategy. Taking these findings a step further, our current study investigated the relations between achievement goal orientations and learning strategies.

\section{Developmental Changes in Relations}

Anderman and Anderman (1999) found that students' mastery goal orientations decreased after the transition from elementary to middle school. In contrast, students' performance goal orientations in a middle school increased. Yamauchi and Miki (2000) examined the relations between students' perceptions of their teachers' and parents' goal orientations, their own achievement goal orientations, and learning strategies for both 7th and 9th grade students. The means of perceived mastery orientation, mastery goal orientation, and deep processing were higher among 7th grade students than among 9th grade students. In contrast, the means of perceived performance orientation, performance goal orientation, surface processing, and self-handicapping were higher among 9th grade students than among 7 th grade students. To find out how these relations change over oneyear period within individuals, in our current study we tested the relations between the variables mentioned above by administering questionnaires to the same students a year apart. Furthermore, we also tested the assumption that perceived learning environment (PLE) in grade 7 would directly influence achievement goal orientations in grade 8.

The present study was undertaken to test the following hypotheses.

1) Students' PLE, especially teachers' and parents' attitudes of mastery and performance orientations, influences their goal orientations.

2) One's own PLE affects the intrinsic-extrinsic regulation, and these regulations in their turn play a mediating role between PLE and students' goal orientation.

3) Students' use of learning strategies is related to their goal orientation. Furthermore, there will be two independent streams connecting PLE to strategies.

4) The longitudinal interrelations between all variables present the proactive effects of each of them on students' behavior after one-year period.

We performed hierarchical and multiple regression analyses to explore the possible mediating role of intrinsic-extrinsic regulation, and the relationship between achievement goal orientations and learning strategies. Finally, these analyses were performed to see the longitudinal interrelations between all variables. 


\section{METHOD}

Sample:

The sample consisted of 214 students (112 girls and 102 boys) from a private junior high school in Kyoto. Students in the sample responded to all questions for the first time at the 7 th grade and for the second time at the 8 th grade. Japanese junior high schools cover the 7 th through the 9 th grade. Private junior high schools, which account for about six percent of all junior high schools in Japan, require students to pass an examination to be admitted. The particular private junior high school used in the current study is somewhat unique in that it admits students to its senior high school (10th grade - 12th grade) without an entrance examination as long as students maintain good academic standing. Thus, students in this sample are unique compared to public junior high school students in that, for the most part, they need not go through the process of taking entrance examinations at the end of the 9th grade to get into a public senior high school. Most students in the current study were from middle-class background.

\section{Procedure:}

Assessment questionnaires were administered at two different times. The first one was administered at the 7th grade, three months after students had passed the entrance examination. Students were instructed by their teachers to complete four booklets of questionnaires in their classrooms. Approximately one year later, at the 8 th grade, the same students were asked to respond to the same questionnaires again.

\section{Instruments:}

The questionnaires consisted of four scales. The students were asked to rate each item on a 6-point scale ranging from (1) strongly disagree to (6) strongly agree.

Perceived Learning Environment Scale. A set of items was constructed to assess students' perceptions of teachers' and parents' attitudes of mastery and performance orientation in the classroom and at home. This scale represents a kind of Evaluation and Recognition structure (Ames, 1992). The items were adapted from the scale by Yamauchi and Miki (2000), and were reorganized into two subscales called Mastery Focus and Performance Focus. Some examples of the six Mastery Focus items $(\alpha=.70)$ include: "My teachers would be more pleased to see me learn new things than receive good grades" for school environment and "My family would acknowledge my hard work regardless of my grade" for home environment. Examples from the eight Performance Focus questions $(\alpha=.78)$ include: "My teachers would think that the most important objective is to get good grades" for school environment and "When my tests are returned with low grades, I sometimes do not want to face my family" for home environment.

Goal Orientations Scale. This scale is an adaptation of Yamauchi and Tanaka's (1998) Self-Regulated Learning Scale for elementary school children, with a minor change in wording adapted for junior high school students. ${ }^{1}$

Students were asked to rate their agreement toward three types of achievement goal orientations: four items for Mastery Orientation, four items for Performance Orientation, and five items for Work-Avoidance Orientation. An example of Mastery Orientation $(\alpha=.75)$ is "I want to be taught new topics until I understand them". Performance Orientation $(\alpha=.75)$ is measured by questions such as "I study hard to get better marks than other students." A sample of Work-Avoidance Orientation $(\alpha=.78)$ is "I want to finish my homework with the least amount of effort".

Learning Strategies Scale. This scale is also an adaptation from the Self-Regulated Learning Scale of Yamauchi and Tanaka (1998) for elementary school children, with a minor change in wording adapted for junior high school students. ${ }^{2}$

Students' self-reported learning strategy was examined using three types of subscales: Deep Processing, Surface Processing, and Self-Handicapping. There were four items for Deep Processing $(\alpha=.61)$ including "I test myself to check if I understood what I had studied", two items for Surface Processing

\footnotetext{
1, 2 Self-Regulated Learning Scale originates from Prof. Markku Niemivirta's Motivational Beliefs and Strategy Questionnaire in his early work. We acknowledge the fact that the Self-Handicapping Scale does not reflect learning strategies as such. It rather assesses the use of behavioral avoidance strategies and tendencies related to academic settings (cf. 'academic withdrawal' in Niemivirta, this issue). However, for the sake of simplicity, it is grouped with the scales for learning strategy use.
} 
$(\alpha=.67)$ such as "In preparing for a test, I only study sections that I am told will be on the test", and threeitems for Self-Handicapping $(\alpha=.61)$, for example, "Occasionally I am tempted to do something else while working on difficult homework".

Intrinsic-Extrinsic Regulation Scale. Students' regulation was assessed using four subscales based on Ryan and Connell's (1989) motivational regulations: Intrinsic Regulation, Identified Regulation, Introjected Regulation, and External Regulation. For each type, we created several situations on the basis of individual levels of motivation in schoolwork. Intrinsic Regulation $(\alpha=.79)$ has four items and deals with behavior originated from inherent enjoyment or fun; "I study new subjects because I find it enjoyable to do so" and "I study for tests because I enjoy it". Identified Regulation $(\alpha=.72)$ has four questions and concerns actions based on one's own values of one's goals: "I study hard for tests because getting good marks will affect my future progress" and "I listen to teachers attentively because I want to understand them". Introjected Regulation $(\alpha=.72)$ has three items and taps internal, esteem-based pressures to act such as avoidance of guilt and shame or concerns about self- and others' approval; "I study new subjects because I want my friends to think that I am bright" and "I listen to teachers because I want them to think that I am a good student". External Regulation $(\alpha=.69)$ has four items and concerns the situation where behavior is explained in terms of external authority, fear of punishment, or rule compliance; "I listen to teachers attentively because I will be reprimanded if I do not" and "I work for tests not to upset my family with poor marks".

\section{RESULTS}

Scores for each subscale were calculated by adding item scores. Means and standard deviations for subscales in grades 7 and 8 are shown in Table 1. To assess the significance of these mean differences, two-way ANOVAs were performed. The ANOVAs were 2 (gender) $\times 2$ (grade) with the second factor being a within factor. We also computed correlation coefficients for every subscale for the two grades. The results are shown in Tables I and II in the Appendix.

\section{Developmental Changes of Mean Scores}

As Table 1 illustrates, the mean scores for Performance Focus in PLE, $F(1$, $212)=11.38, p<.001$, Work-Avoidance in goal orientations, $F(1,212)=31.22, p<.001$, and Surface Processing and Self-Handicapping in learning strategies, $F(1,212)=14.20, p<.001$ and $F(1,212)=10.66, p<.001$ respectively, increased significantly over the one-year interval. In contrast, the mean scores for Mastery Focus in PLE, $F(1,212)=52.92, p<.001$, Intrinsic Regulation and Identified Regulation in intrinsic-extrinsic regulation, $F(1$, $212)=46.06, p<.001$ and $F(1,212)=62.25, p<.001$ respectively, Mastery Orientation in goal orientations, $F(1,212)=104.55, p<.001$, and Deep Processing in learning strategies, $F(1,212)=24.18, p<.001$, decreased significantly over the period passed. Significant interaction effects were found on Mastery Focus, $F(1,212)=4.75, p<.05$, WorkAvoidance, $F(1,212)=4.18, p<.05$, and Self-Handicapping, $F(1,212)=5.75, p<.05$. These interactions show that the decreasing of mean scores for Mastery Focus was more marked among girls than among boys and the increasing of mean scores for Work-Avoidance and Self-Handicapping were more marked among girls than among boys.

\section{Perceived Learning Environments as Predictors of Achievement Goal Orientations}

Table 2 presents the results of hierarchical regression analysis for the relations between students' PLE and goal orientations in grade 7 (Step 1). In the first step of these 


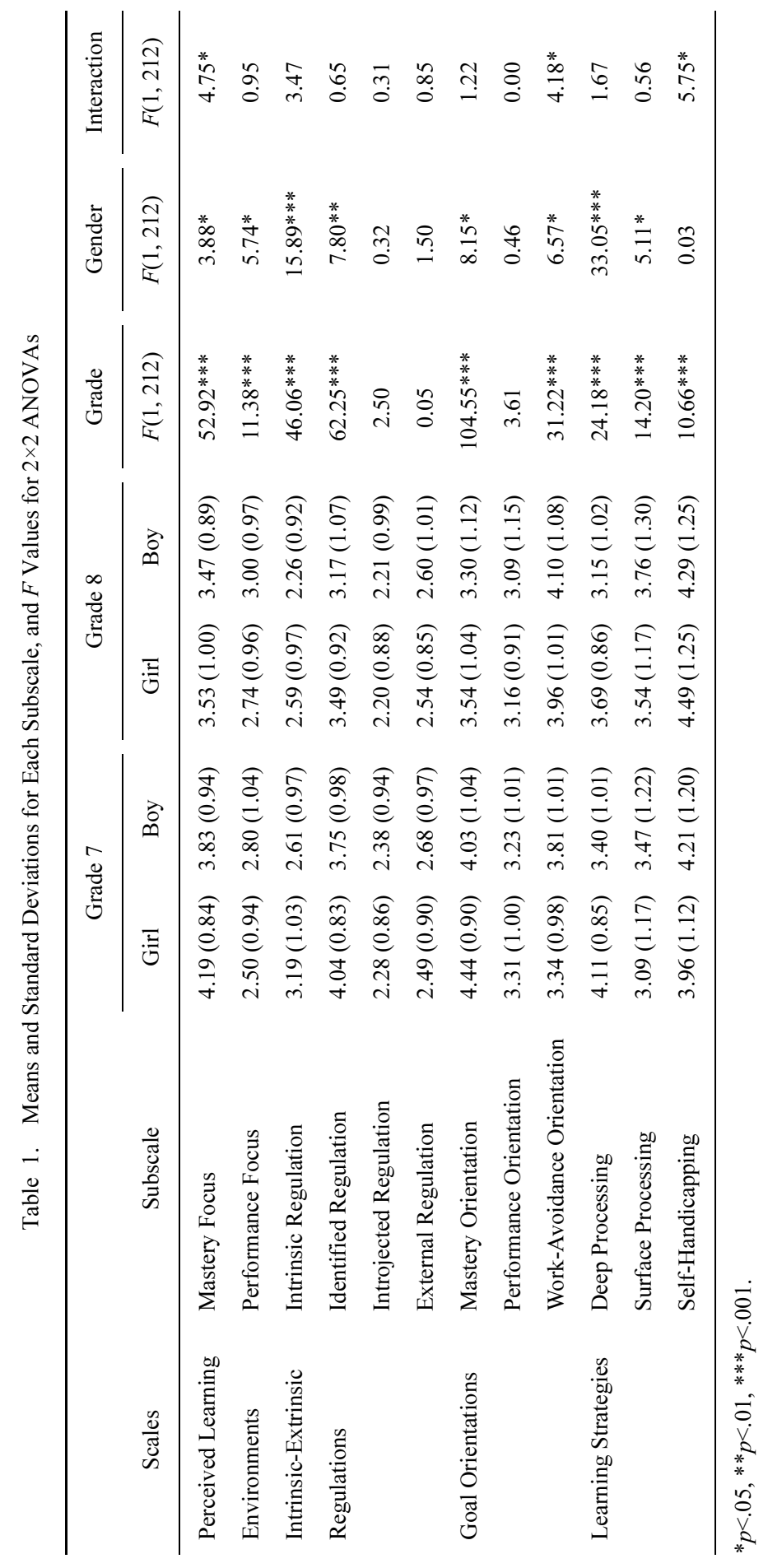


Table 2. Hierarchical Regression Predicting Goal Orientation in Grade 7

\begin{tabular}{|c|c|c|c|c|c|c|}
\hline \multirow[b]{3}{*}{ Predictor } & \multicolumn{6}{|c|}{ Criterion Variable } \\
\hline & \multicolumn{2}{|c|}{ Mastery Orientation } & \multicolumn{2}{|c|}{ Performance Orientation } & \multicolumn{2}{|c|}{ Work-Avoidance } \\
\hline & $\beta$ Step 1 & $\beta$ Step 2 & $\beta$ Step 1 & $\beta$ Step 2 & $\beta$ Step 1 & $\beta$ Step 2 \\
\hline \multicolumn{7}{|l|}{ Step 1} \\
\hline Mastery Focus & $0.42 * * *$ & $0.16^{* *}$ & 0.09 & -0.09 & $-0.22 * *$ & -0.04 \\
\hline Pefrormance Focus & 0.06 & -0.07 & $0.28 * * *$ & 0.06 & 0.10 & 0.04 \\
\hline \multicolumn{7}{|l|}{ Step 2} \\
\hline Intrinsic Regulation & & $0.31 * * *$ & & 0.02 & & $-0.40 * * *$ \\
\hline Identified Regulation & & $0.41 * * *$ & & $0.27 * * *$ & & -0.07 \\
\hline Introjected Regulation & & -0.10 & & $0.47 * * *$ & & 0.09 \\
\hline External Regulation & & 0.07 & & 0.06 & & $0.17 *$ \\
\hline$R^{2}$ & $0.16^{* * *}$ & $0.48 * * *$ & $0.07 * * *$ & $0.42 * * *$ & $0.07 * * *$ & $0.24 * * *$ \\
\hline Change in $R^{2}$ & & $0.32 * * *$ & & $0.35 * * *$ & & $0.17 * * *$ \\
\hline
\end{tabular}

${ }^{*} p<.05, * * p<.01, * * * p<.001$

analyses, Mastery Focus was a significant predictor for Mastery Orientation and WorkAvoidance $(\beta=.42$ and $\beta=-.22$ ), and Performance Focus was a significant predictor for Mastery Orientation $(\beta=.28)$. The variables of students' perceived learning environments accounted for $16 \%$ of Mastery Orientation, $7 \%$ of Performance Orientation, and $7 \%$ of Work-Avoidance Orientation.

\section{Intrinsic-Extrinsic Regulation as Mediators}

The effects of intrinsic-extrinsic regulation as a mediator between the above variables were tested by $\beta$ s from the second step in Table 2 , and by $\beta$ s in Table 3 . As shown in Table 2, when the variables of regulation were added to the equation, the coefficient of Mastery Focus for Mastery Orientation dropped to .16 but this is still significant at the .01 level (step 2). Mastery Orientation accounted for an additional $32 \%$ of the variance in the four types of motivation $\left(R^{2}=.48\right)$, and Intrinsic Regulation and Identified Regulation were significant predictors for Mastery Orientation $(\beta=.31$ and $\beta=.41$ ). Similarly, the coefficient of Performance Focus for Performance Orientation dropped to .06 when the variables of regulation were added to the equation. Performance Orientation accounted for an additional $35 \%$ of the variance in the four types of regulation $\left(R^{2}=.42\right)$, and Identified Regulation and Introjected Regulation were significant predictors for Performance Orientation ( $\beta=.27$ and $\beta=.47$ ). Further, when the variables of regulation were added to the equation the coefficient of Mastery Focus for Work-Avoidance Orientation dropped to -.04 . Work-Avoidance Orientation accounted for an additional 
Table 3. Multiple Regression Predicting Intrinsic-Extrinsic Regulations in Grade 7

\begin{tabular}{|c|c|c|c|c|}
\hline \multirow[b]{3}{*}{ Predictor } & \multicolumn{4}{|c|}{ Criterion Variable } \\
\hline & Intrinsic Regulation & Identified Regulation & Introjected Regulation & External Regulation \\
\hline & $\beta$ & $\beta$ & $\beta$ & $\beta$ \\
\hline Mastery Focus & $0.42 * * *$ & $0.34 * * *$ & $0.16^{*}$ & -0.02 \\
\hline Performance Focus & 0.09 & $0.20 * *$ & $0.28 * * *$ & $0.53 * * *$ \\
\hline$R^{2}$ & $0.16^{* * *}$ & $0.12 * * *$ & $0.08 * * *$ & $0.29 * * *$ \\
\hline
\end{tabular}

${ }^{*} p<.05,{ }^{* *} p<.01,{ }^{* * *} p<.001$.

$17 \%$ of variance in the four types of regulation $\left(R^{2}=.24\right)$, and Intrinsic Regulation and External Regulation were significant predictors for Performance Orientation $(\beta=-.40$ and $\beta=.17)$.

To further explore the relative influence of students' perceived learning environments on regulation, multiple regression analysis was used for the four types of regulation as the criterion variables. Table 3 presents the multiple regression coefficients $(\beta s)$.

Students' perceived learning environments as predictor variables accounted for $16 \%$ of Intrinsic Regulation, 12\% of Identified Regulation, 8\% of Introjected Regulation, and $29 \%$ of External Regulation. Mastery Focus was significantly associated with Intrinsic Regulation, Identified Regulation, and Introjected Regulation $(\beta=.42, \beta=.34$, and $\beta=.16$, respectively). On the other hand, Performance Focus was significantly associated with External Regulation, Introjected Regulation, and Identified Regulation $(\beta=.53, \beta=.28$, and $\beta=.20$, respectively).

\section{Learning Strategies as Criterion Variables}

To further illuminate the relationship between students' PLE, intrinsic-extrinsic regulations, achievement goal orientations and learning strategies, hierarchical regression analysis was used with the learning strategy as the criterion variable. The results of the analyses are presented in Table 4.

As shown in Table 4, Mastery Focus was a significant predictor for Deep Processing in the first step of these analyses $(\beta=.29)$. However, when regulations were added to the equation, the coefficient of Intrinsic Regulation and Identified Regulation were significant predictors $(\beta=.29$ and $\beta=.32$ ) for Deep Processing (step 2). In the third step, Mastery Orientation and Work-Avoidance Orientation were significant predictors for Deep Processing $(\beta=.33$ and $\beta=-.14)$, and Identified Regulation still remained a significant predictor $(\beta=.15)$. With respect to Surface Processing as the criterion variable, Intrinsic Regulation and External Regulation were significant predictors in step $2(\beta=-.32$ and $\beta=.26)$ and in step $3(\beta=-.20$ and $\beta=.20)$, and Work-Avoidance Orientation was also a significant predictor $(\beta=.31)$. Performance Focus was a significant predictor for Self- 
Table 4. Hierarchical Regression Predicting Learning Strategies in Grade 7

\begin{tabular}{|c|c|c|c|c|c|c|c|c|c|}
\hline \multirow[b]{3}{*}{ Predictor } & \multicolumn{9}{|c|}{ Criterion Variable } \\
\hline & \multicolumn{3}{|c|}{ Deep Processing } & \multicolumn{3}{|c|}{ Surface Processing } & \multicolumn{3}{|c|}{ Self-Handicapping } \\
\hline & $\beta$ Step 1 & $\beta$ Step 2 & $\beta$ Step 3 & $\beta$ Step 1 & $\beta$ Step 2 & $\beta$ Step 3 & $\beta$ Step 1 & $\beta$ Step 2 & $\beta$ Step 3 \\
\hline \multicolumn{10}{|l|}{ Step 1} \\
\hline Mastery Focus & $0.29 * * *$ & 0.08 & 0.03 & -0.13 & 0.02 & 0.04 & -0.10 & 0.01 & 0.04 \\
\hline $\begin{array}{l}\text { Pefrormance } \\
\text { Focus }\end{array}$ & 0.09 & 0.01 & 0.04 & 0.10 & 0.02 & 0.01 & $0.214 * * *$ & $0.16^{*}$ & 0.15 \\
\hline \multicolumn{10}{|l|}{ Step 2} \\
\hline $\begin{array}{l}\text { Intrinsic } \\
\text { Regulation }\end{array}$ & & $0.29 * * *$ & 0.13 & & $-0.32 * * *$ & $-0.20^{*}$ & & $-0.20 *$ & -0.10 \\
\hline $\begin{array}{l}\text { Identified } \\
\text { Regulation }\end{array}$ & & $0.32 * * *$ & $0.15^{*}$ & & -0.02 & -0.02 & & -0.06 & -0.07 \\
\hline $\begin{array}{l}\text { Introjected } \\
\text { Regulation }\end{array}$ & & -0.12 & -0.11 & & -0.08 & -0.14 & & -0.04 & -0.13 \\
\hline $\begin{array}{l}\text { External } \\
\text { Regulation }\end{array}$ & & 0.03 & 0.03 & & $0.26 * * *$ & $0.20^{*}$ & & $0.23 * *$ & $0.18^{*}$ \\
\hline Step 3 & & & & & & & & & \\
\hline $\begin{array}{l}\text { Mastery } \\
\text { Orientation }\end{array}$ & & & $0.33 * * *$ & & & 0.02 & & & -0.01 \\
\hline $\begin{array}{l}\text { Performance } \\
\text { Orientation }\end{array}$ & & & 0.07 & & & 0.06 & & & 0.15 \\
\hline $\begin{array}{l}\text { Work-Avoidance } \\
\text { Orientation }\end{array}$ & & & $-0.14^{*}$ & & & $0.31 * * *$ & & & $0.24 * * *$ \\
\hline$R^{2}$ & $0.08 * * *$ & $0.29 * * *$ & $0.37 * * *$ & $0.04 *$ & $0.17 * * *$ & $0.25^{* * *}$ & $0.08 * * *$ & $0.16^{* * *}$ & $0.22 * * *$ \\
\hline Change in $R^{2}$ & & $0.21 * * *$ & $0.08 * * *$ & & $0.13 * * *$ & $0.08 * * *$ & & $0.08 * * *$ & $0.06^{* *}$ \\
\hline
\end{tabular}

$* p<.05, * * p<.01, * * * p<.001$.

Handicapping in steps 1 and $2(\beta=.24$ and $\beta=.16)$, and Intrinsic Regulation and External Regulation were also significant predictors in step $2(\beta=-.20$ and $\beta=.23)$. In the third step, External Regulation and Work-Avoidance Orientation were significant predictors for SelfHandicapping ( $\beta=.18$ and $\beta=.24)$.

Fig. 1 shows a path diagram of perceived environments, regulations, goal orientations, and learning strategies. Path values are standardized regression coefficients $(p<.01)$ shown in Tables 2, 3, and 4, and the broken line represents a negative path.

\section{Longitudinal Effects of Variables}

To explore the longitudinal effects of perceived environments, regulations, 


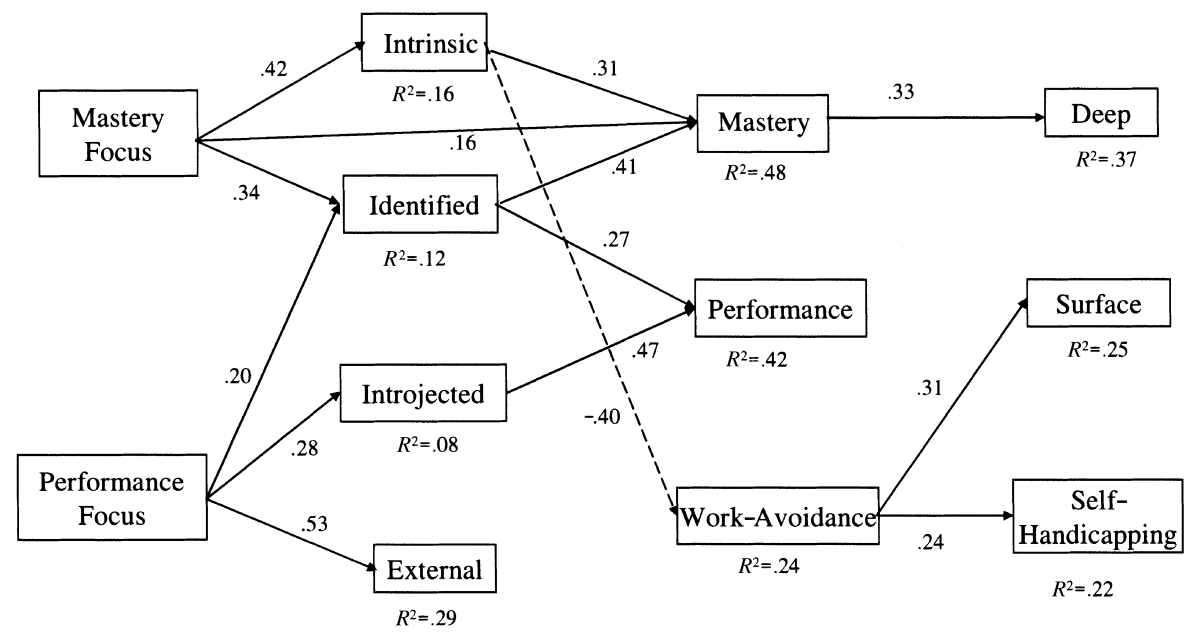

$\begin{array}{lll}\text { Perceived } & \text { Regulations } & \text { Goal Orientations } \\ \text { Environments } & \text { Learning Strategies }\end{array}$

Fig. 1. The path diagram of perceived environments, regulations, goal orientations, and learning strategies in grade 7 .

Note: The broken line represents a negative path.

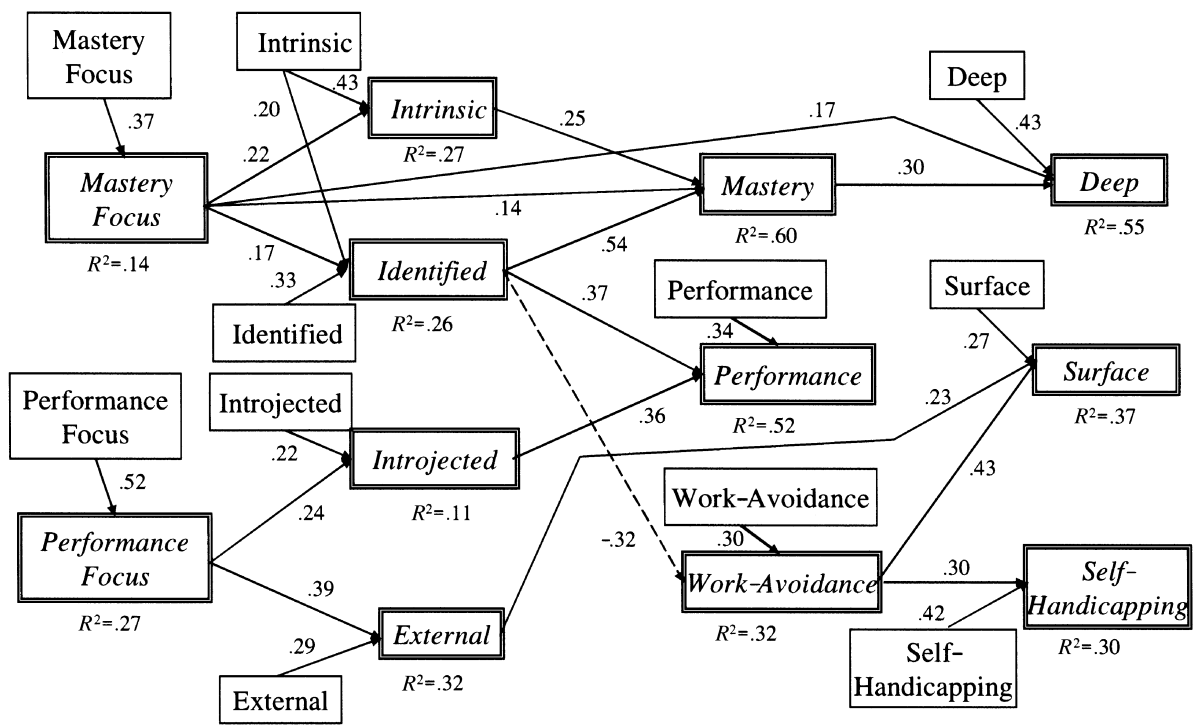

$\begin{array}{lll}\text { Perceived } & \text { Gegulations } & \text { Goal Orientations } \\ \text { Environments } & \text { Learning Strategies }\end{array}$

Fig. 2. The path diagram of all variables from the longitudinal data.

Note 1: Standard fonts in single frames represent variables in grade 7 and italic fonts in doubled frames represent variables in grade 8 .

Note 2: The broken line represents a negative path. 
Table 5. Hierarchical Regression Predicting Goal Orientation in Grade 8

\begin{tabular}{|c|c|c|c|c|c|c|}
\hline \multirow[b]{3}{*}{ Predictor (Grade 7) } & \multicolumn{6}{|c|}{ Criterion Variable (Grade 8) } \\
\hline & \multicolumn{2}{|c|}{ Mastery Orientaiton } & \multicolumn{2}{|c|}{ Performance Orientation } & \multicolumn{2}{|c|}{ Work-Avoidance } \\
\hline & $\beta$ Step 1 & $\beta$ Step 2 & $\beta$ Step 1 & $\beta$ Step 2 & $\beta$ Step 1 & $\beta$ Step 2 \\
\hline \multicolumn{7}{|l|}{ Step 1} \\
\hline Mastery Focus & $0.21 * *$ & 0.05 & $0.19 * *$ & 0.11 & $-0.30 * *$ & $-0.17^{*}$ \\
\hline Performance Focus & -0.07 & -0.05 & $0.19 * *$ & 0.10 & -0.02 & 0.02 \\
\hline \multicolumn{7}{|l|}{ Step 2} \\
\hline Intrinsic Regulation & & $0.23 * *$ & & -0.04 & & $-0.18^{*}$ \\
\hline Identified Regulation & & $0.26 * * *$ & & $0.24 * *$ & & -0.10 \\
\hline Introjected Regulation & & -0.18 & & 0.07 & & -0.06 \\
\hline External Regulation & & 0.08 & & 0.05 & & 0.11 \\
\hline$R^{2}$ & $0.06 * *$ & $0.21 * * *$ & $0.05 * *$ & $0.11 * * *$ & $0.08 * * *$ & $0.15 * * *$ \\
\hline Change in $R^{2}$ & & $0.16^{* * *}$ & & $0.06 * *$ & & $0.06 * *$ \\
\hline
\end{tabular}

${ }^{*} p<.05,{ }^{* *} p<.01,{ }^{* * *} p<.001$.

achievement goal orientations, and learning strategies, we performed four steps of multiple regression analysis by altering criterion variables as follows; (1) perceived environments in grade 8, (2) intrinsic-extrinsic regulations in grade 8, (3) achievement goal orientations in grade 8, and (4) learning strategies in grade 8. For example, when Deep Processing in learning strategies is the criterion variable, every subscale in grades 7 and 8 of perceived learning environments, intrinsic-extrinsic regulations, and goal orientations were predictors. Fig. 2 shows the path diagram of these results. Variables from grade 7 are represented in a standard font inside single frames, while variables from grade 8 are represented in an italic font inside doubled frames. Path values are standardized regression coefficients $(p<.01)$ and the broken line represents a negative path.

In general, most variables were influenced by the respective variables from the previous year. There were two streams of effects: one from Mastery Focus to Mastery Orientation and the other from Performance Focus to Performance Orientation. While there was a direct path from Mastery Focus to Mastery Orientation as well as indirect paths via Intrinsic Regulation and Identified Regulation, there was only an indirect path from Performance Focus to Performance Orientation via Introjected Regulation. As shown in Fig. 2, the sequence of perceived environments, regulations, goal orientations, learning strategies in grades 7 and 8 were similar to each other except for a few differences. There was a negative path from Intrinsic Regulation to Work-Avoidance in grade 7 , and there was a negative path from Identified Regulation to Work-Avoidance in 
grade 8. In grade 8, Mastery Focus affected Deep Processing, and External Regulation influenced Surface Processing.

In Hypothesis 4, we expected a proactive effect in the longitudinal analysis, that is, that perceived learning environment in grade 7 would directly influence achievement goal orientations in grade 8. However, this was not verified in the results, as shown in Fig. 2. To further illuminate such longitudinal relationships between PLE, intrinsic-extrinsic regulations, achievement goal orientation, and learning strategies, hierarchical regression analysis was carried out with the subscale values in grade 8 as the criterion variables and those in grade 7 as the predictors. We ignored the subscale values in grade 8 as the predictors, because the proactive effects were weaker than the effects of concurrent variables. Table 5 shows the results of hierarchical regression analyses of achievement goal orientations in grade 8 as criterion variables, and perceptions of mastery and performance focuses in grade 7 (step 1) and intrinsic-extrinsic regulations in grade 7 (added on step 2) as predictors. As shown in Table 5, significant proactive effects were obtained from some predictors. In the case of learning strategies in grade 8 as criterion variables, however, most of predictors did not show significant proactive effects.

\section{DISCUSSION}

Using Vallerand's (1997) hierarchical model of motivation, Yamauchi (2002) suggested two streams of effects in his data analyses. The first stream included more selfregulated attributes and the second stream contained less self-regulated variables. In our current study, more self-regulated variables such as Mastery Focus, Intrinsic Regulation, Identified Regulation, Mastery Orientation, and Deep Processing had significantly decreased their effects after a one-year period. On the other hand, less self-regulated variables such as Performance Focus, Work-Avoidance Orientation, Surface Processing, and Self-Handicapping had significantly increased their effects (see Table 1). These findings are consistent with the results of Yamauchi and Miki (2000) and suggest interesting effects of students' academic conditions on their behavior. When the students responded to the questionnaires at grade 7 , it had only been three months since they had entered this private school so they might have been very curious and motivated by their new surroundings. On the other hand, by the time students advanced into the 8 th grade, they might have been aware of the fact that they needed good grades to be accepted into the senior high school which might have led them to be more concerned with achieving high scores in tests than before.

Our first hypothesis was that students' PLE would influence their goal orientation. As shown in Table 2, Mastery Focus significantly influenced Mastery Orientation. This influence was observed through three paths: the first is a direct path and the others are two indirect paths mediated by Intrinsic Regulation and Identified Regulation. In contrast, Performance Focus significantly affected Performance Orientation through Introjected Regulation as a mediator. However, Performance Orientation was also influenced by Mastery Focus via Identified Regulation. Furthermore, Work-Avoidance Orientation was 
inversely affected by Intrinsic Regulation in grade 7 and Identified Regulation in grade 8 (see Figs. 1 and 2). With regard to the relationship between PLE and achievement goal orientation, Mastery Focus influenced all three types of goal orientation while Performance Focus affected only Performance Orientation. Furthermore, Mastery Focus significantly influenced Deep Processing in grade 8. Therefore, students' PLE had different meanings on their achievement goal orientation. The second hypothesis was that the PLE affects the intrinsic-extrinsic regulations and these regulations in turn would play a mediating role between PLE and goal orientation. As mentioned previously, the results shown in Tables 2 and 3 suggested that the intrinsic-extrinsic regulations had a mediating role between PLE and goal orientation.

The third hypothesis was that students' use of learning strategies would be related to goal orientation, and furthermore, there would be two streams from PLE to strategies. The effects of goal orientation on learning strategies were differentiated depending on the strategies (see Fig. 1). On the whole, Mastery Orientation was a predictor for Deep Processing, while Work-Avoidance Orientation was a predictor for Surface Processing and for Self-Handicapping. Although performance goal oriented students are known to be involved in surface strategy processing (Ames, 1992; Pintrich \& De Groot, 1990; Yamauchi \& Tanaka, 1998), Performance Orientation in this study did not have any pathways to learning strategies in either grade. Instead, Work-Avoidance Orientation showed a significant pathway to Surface Processing. Although the reason for Performance Orientation not influencing Surface Processing is unclear at this moment, one possible explanation may come from Elliot and Harackiewicz's (1996) goal theory. In addition to mastery goal, they distinguished two dimensions in performance goals; performance-approach goal to demonstrate superior ability, and performance-avoidance goal to avoid the demonstration of lack of ability. Performance Orientation items in the current study had characteristics of performance-approach goal, but not characteristics of performance-avoidance. Had performance-avoidance characteristics been included in the goal orientation, the pathway from Work-Avoidance Orientation to Surface Processing might have been replaced with a pathway from Performance Orientation to Surface Processing. Following the previous research (Pintrich \& Garcia, 1994; Yamauchi \& Tanaka, 1998), Work-Avoidance Orientation significantly influenced Self-Handicapping strategy. Deep Processing showed a direct influence from Identified Regulation, and Surface Processing and Self-Handicapping indicated a direct pathway from External Regulation (see Table 4).

In summary, regression analyses in this study suggested two streams of effects: (1) more autonomous motivation and self-regulated attributes, and (2) less autonomous motivation and self-regulated attributes. We were able to show that the first stream decreased and that the second stream increased after one year. Regarding the first stream, the achievement goal orientation was influenced directly and indirectly by students' perceptions of learning environment. In contrast, there was only an indirect effect towards goal orientation in the second stream. We need more information on the pathway from performance goal orientation to surface processing in order to draw specific conclusions.

The fourth hypothesis was that the longitudinal interrelations between all variables 
would present the proactive effects after the period of one year. We examined if grade 7 variables influenced grade 8 variables. We expected, for example, that perceived learning environment in grade 7 would directly influence achievement goal orientations in grade 8 . It is clear that all variables in grade 7 influenced the same variables in grade 8 , but we could not find any variables affecting different variables (see Figs. 1 and 2). When we ignored all predictors in grade 8 to emphasize the proactive effects from predictors in grade 7, significant proactive effects were obtained from some predictors as expected (see Table 5).

\section{REFERENCES}

Ames, C. 1992. Classrooms: Goals, structures, and student motivation. Journal of Educational Psychology, 84, 261-271.

Ames, C., \& Archer, J. 1988. Achievement goals in the classroom: Students' learning strategies and motivation processes. Journal of Educational Psychology, 80, 260-267.

Anderman, L. H., \& Anderman, E. M. 1999. Social predictors of changes in students' achievement goal orientations. Contemporary Educational Psychology, 25, 21-37.

Anderman, E. M., \& Midgley, C. 1997. Changes in achievement goal orientations, perceived academic competence, and grades across the transition to middle level schools. Contemporary Educational Psychology, 22, 269-298.

Blumenfeld, P. C. 1992. Classroom learning and motivation: Clarifying and expanding goal theory. Journal of Educational Psychology, 84, 272-281.

Church, M. A., Elliot, A. J., \& Gable, S. L. 2001. Perceptions of classroom environment, achievement goal, and achievement outcomes. Journal of Educational Psychology, 93, 43-54.

Deci, E. L. 1975. Intrinsic motivation. New York: Plenum.

Deci, E. L., \& Ryan, R. M. 1985. Intrinsic motivation and self-determination in human behavior. New York: Plenum.

Duda, J. L., \& Nicholls, J. G. 1992. Dimensions of achievement motivation in schoolwork and sport. Journal of Educational Psychology, 80, 260-267.

Dweck, C., \& Leggett, E. L. 1988. A social-cognitive approach to motivation and personality. Psychological Review, 95, 256-273.

Elliot, A. J., \& Church, M. A. 1997. A hierarchical model of approach and avoidance achievement motivation. Journal of Personality and Social Psychology, 72, 218-232.

Elliot, A. J., \& Harackiewicz, J. M. 1996. Approach and avoidance achievement goals and intrinsic motivation: A mediational analysis. Journal of Personality and Social Psychology, 70, 461-475.

Elliot, A. J., \& McGregor, H. A. 2001. A $2 \times 2$ achievement goal framework. Journal of Personality and Social Psychology, 80, 501-519.

Epstein, J. L. 1988. Effective schools or effective students: Dealing with diversity. In R. Haskins \& D. MacRae (Eds.), Policies for America's public schools: Teachers, equity, and indicators (pp. 89-126). Norwood, NJ: Ablex.

Epstein, J. L. 1989. Family structures and student motivation: A developmental perspective. In C. Ames \& R. Ames (Eds.), Research in motivation in education: Goals and cognitions (Vol. 3, pp. 259-295). New York: Academic.

Maehr, M. L., \& Midgley, C. 1991. Enhancing student motivation: A school-wide approach. Educational Psychologist, 26, 399-427.

Midgley, C., Kaplan, A., \& Middleton, M. 2001. Performance-approach goals: Good for what, for whom, under what circumstances, and at what cost? Journal of Educational Psychology, 93, 77-86.

Nicholls, J. G. 1984. Achievement motivation: Conceptions of ability, subjective experience, task choice, and performance. Psychological Review, 91, 328-346.

Niemivirta, M. 1998a. Individual differences in motivational and cognitive factors affecting self-regulated 
learning: A pattern-oriented approach. In P. Nenniger, R. S. Jäger, A. Frey, \& M. Wosnitza (Eds.), Advances in motivation (pp. 23-42). Landau, Germany: Verlag Empirische Pädagogik.

Niemivirta, M. 1998b. Stability and change in goal orientations and motivational beliefs: A pattern-oriented approach. Paper presented at the 24th International Congress of Applied Psychology, San Francisco, U.S.A.

Peltonen, A., \& Niemivirta, M. 1999. Motivation, self-regulation and perceptions of the learning environment. Paper presented at the 8th European Conference for Research on Learning and Instruction, Gothenburg, Sweden.

Pintrich, P. R. 2000. Multiple goals, multiple pathways: The role of goal orientation in learning and achievement. Journal of Educational Psychology, 92, 544-555.

Pintrich, P. R., \& De Groot, E. V. 1990. Motivational and self-regulated learning components of classroom academic performance. Journal of Educational Psychology, 82, 33-40.

Pintrich, P. R., \& Garcia, T. 1991. Student goal orientation and self-regulation in college classroom. In M. L. Maehr \& P. R. Pintrich (Eds.), Advances in motivation and achievement: Goals and self-regulatory processes (pp. 371-402). Greenwich, CT: JAI Press.

Pintrich, P. R., \& Garcia, T. 1994. Self-regulated learning in college students: Knowledge, strategies and motivation. In P. R. Pintrich, D. R. Brown, \& C. E. Weinstein (Eds.), Student motivation, cognition, and learning (pp. 113-133). Hillsdale, NJ: Erlbaum.

Rigby, C. S., Deci, E. L., Patrick, B. D., \& Ryan, R. M. 1992. Beyond the intrinsic-extrinsic dichotomy: Selfdetermination in motivation and learning. Motivation and Emotion, 16, 165-185.

Roeser, R. W., Midgley, C., \& Urdan, T. C. 1996. Perceptions of the school psychological environment and early adolescents' psychological and behavioral functioning in school: The mediating role of goals and belonging. Journal of Educational Psychology, 88, 408-422.

Ryan, R. M., \& Connell, J. P. 1989. Perceived locus of causality and internalization: Examining reasons for acting in two domains. Journal of Personality and Social Psychology, 57, 749-761.

Urdan, T. C., Midgley, F., \& Anderman, E. M. 1998. The role of classroom goal structure in students' use of self-handicapping. American Educational Research Journal, 35, 101-122.

Vallerand, R. J. 1997. Toward a hierarchical model of intrinsic and extrinsic motivation. In M. P. Zanna (Ed.), Advances in experimental social psychology (Vol. 29, pp. 271-360). New York: Academic.

Wolters, C. A., Yu, S. L., \& Pintrich, P. R. 1996. The relation between goal orientation and students' motivational beliefs and self-regulated learning. Learning and Individual Differences, 8, 211-238.

Yamauchi, H. 2002. An approach to the hierarchical model of motivation in a classroom: A reply to Rousseau and Vallerand. Psychological Reports, 90, 273-278.

Yamauchi, H., \& Miki, K. 2000. Effects of students' perception of teachers' and parents' attitudes on their achievement goals and learning strategies. Psychologia, 43, 188-198.

Yamauchi, H., \& Tanaka, K. 1998. Relations of autonomy, self-referenced beliefs, and self-regulated learning among Japanese children. Psychological Reports, 82, 803-816. 


\section{Appendix}

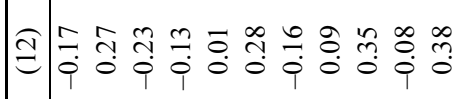

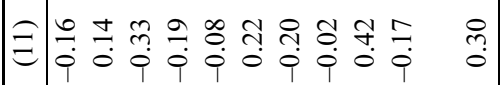

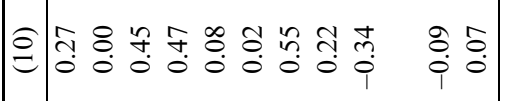

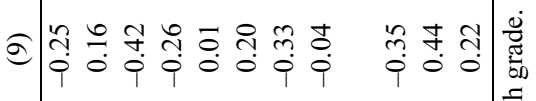

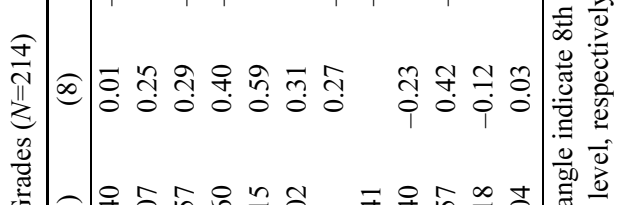

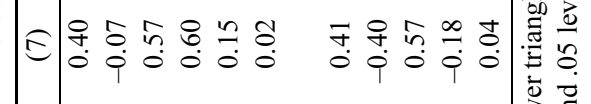

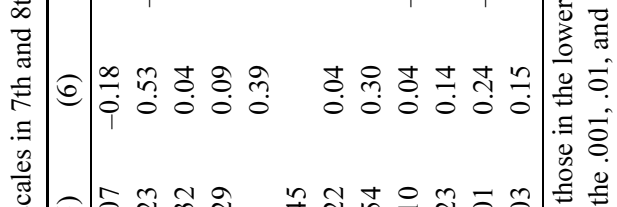

๙

至

壳

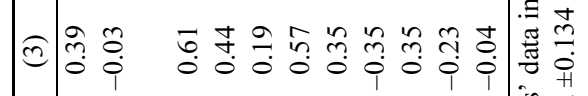

总

-

$\frac{\sqrt{0}}{\frac{9}{\pi}}$

Є 난.

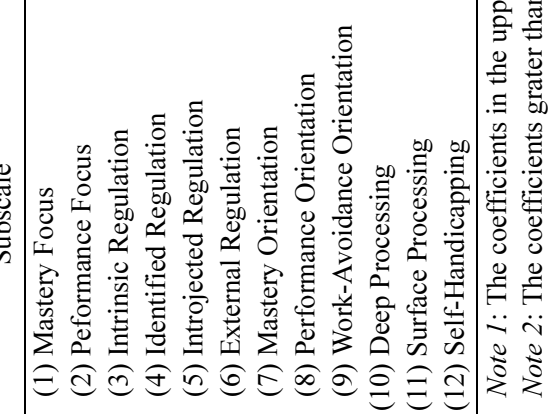

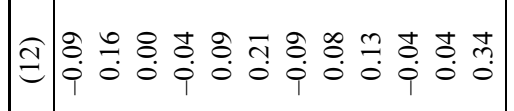

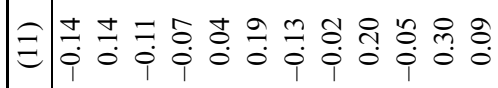

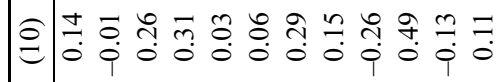

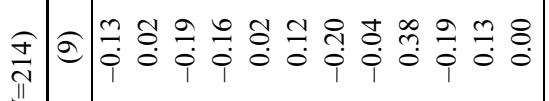

苛

志

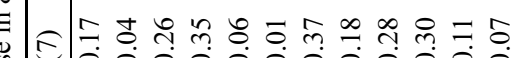

要

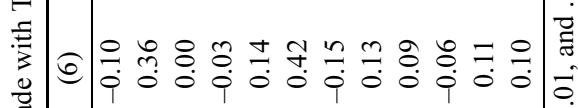

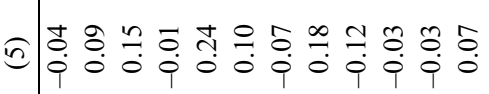

官

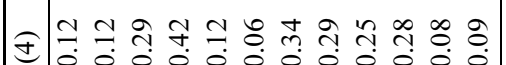

๙ิ

ठํํำ

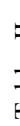

离

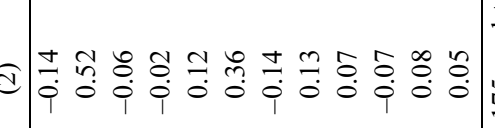

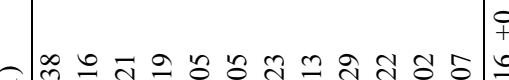

$\stackrel{1}{\circ}$

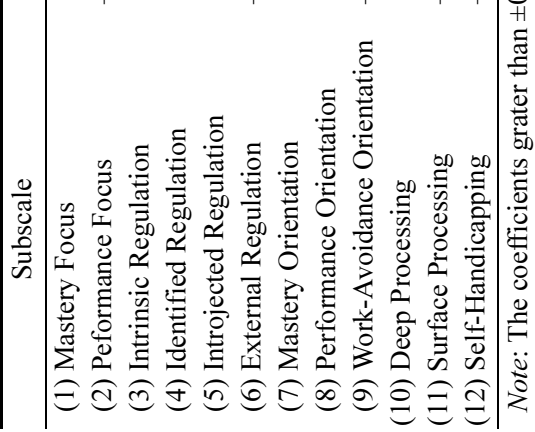

